\title{
De Vida Infantil à Vida Juvenil: uma jornada pelos
} arquivos

\author{
From Vida Infantil to Vida Juvenil: a journey through
}

the archives

\author{
Mariana Elena PinHeIRo dos SANTOS DE SOUZA (id
}

\section{Resumo}

O presente artigo visa traçar um panorama relativo à pesquisa em arquivos, com especial ênfase nos arquivos físicos. Busca-se narrar o processo de pesquisa vivenciado tanto no âmbito do mestrado, finalizado em 2019, quanto no do doutorado, em curso. Ambas as pesquisas têm como objeto e fonte periódicos, cuja guarda encontra-se na Seção de Periódicos, da Fundação Biblioteca Nacional (FBN), o que possibilita tratar do modo de operação de pesquisa em arquivos físicos.

Palavras-chave: Pesquisa. História. Arquivos. Periódicos.

\begin{abstract}
This paper aims to present an overview regarding research in archives, with a special focus on physical archives. It aims to narrate the research process experienced in both Master (finished in 2019) and Doctorate (on course) degrees. Both researches have journals as object and source. Such journals can be found in the Journal Section of the Fundação Biblioteca Nacional (FBN), what allows us to present ways of researching in physical archives.
\end{abstract}

Keywords: Research. History. Archives. Journals.

Resumen

\footnotetext{
${ }^{1}$ Colégio de Aplicação da Universidade Federal do Rio de Janeiro. E-mail: marianaepss@gmail.com
} 
El presente artículo busca presentar un panorama relativo a la pesquisa en archivos, con una especial mirada en los archivos físicos. Se busca narrar el proceso de pesquisa vivido tanto durante la maestría, finalizada en 2019, cuanto en el doctorado, en curso. Ambas las pesquisas tienen como objeto y fuente periódicos que se encuentran en la Sección de Periódicos de la Fundação Biblioteca Nacional (FBN), lo que posibilita presentar el modo de búsqueda en archivos físicos.

Palabras clave: Pesquisa. Historia. Archivos. Periódicos.

\section{Introdução}

Este artigo busca apresentar o caminho traçado quando das pesquisas de mestrado (2017-2019) e de doutorado (2021-em curso), com especial enfoque no que concerne ao modo de operação em arquivos físicos. Trata-se de um movimento inicial em relação a pensar sobre o processo de pesquisa em arquivos físicos, mas que se coloca bastante pertinente no contexto atual de escrita deste artigo.

Desde 2020, temos enfrentado a pandemia causada pelo novo Coronavírus, o que tem nos obrigado a cumprir quarentena e praticar o distanciamento social. Neste sentido, muitas atividades que antes eram realizadas de maneira presencial puderam ser substituídas, parcial ou integralmente, por atividades remotas. A pesquisa em arquivos físicos, contudo, não foi uma destas atividades que puderam ser substituídas pelo modelo remoto - o que nos instiga, ainda mais, a pensar o espaço de arquivos e bibliotecas no processo investigativo.

Destarte, no âmbito do artigo busca-se salientar aspectos gerais referente à pesquisa em arquivos e, de maneira mais específica, o espaço dos arquivos físicos nas pesquisas empreendidas por mim. Ademais, busca-se iluminar elementos das revistas analisadas: Vida Infantil e Vida Juvenil. As revistas em destaque se encontram sob guarda da Seção de Periódicos, da Fundação Biblioteca Nacional (FBN), localizada no Centro da cidade do Rio de Janeiro.

Cabe ressaltar que Vida Infantil foi o periódico analisado no mestrado e a pesquisa atual, de doutorado, tem se debruçado em Vida Juvenil. Como se nota, os nomes das revistas parecem ter relação, ainda que os públicos visados sejam distintos. Se por um lado Vida Infantil era endereçada às crianças, Vida Juvenil, por outro, tinha os jovens como público ideal, conforme será possível observar ao longo do artigo. Rev. Caminhos da Educação: diálogos, culturas e diversidades, Teresina, v. 3, n. 2, p. 53-65, Mai./Ago. 2021 
Importa destacar, ainda, que a escolha por me debruçar em duas revistas para pensar em aspectos do campo da História da Educação não se deu de maneira fortuita. Nesse sentido, utilizo as contribuições de Bloch (2001) acerca da guinada da história e da escrita da história, vislumbrada, em grande medida, a partir do Movimento da Escola dos Annales (1929), de modo a ser possível localizar o espaço de Vida Infantil e Vida Juvenil na condição de fontes históricas e de materiais sociais, frutos de um tempo e de um espaço.

Ademais, traço um diálogo com Nunes e Carvalho (2005) no que diz respeito à defesa de que se faz necessário problematizar e alargar a concepção de fontes nas pesquisas em História da Educação. As autoras ressaltam a relação entre a Nova História Cultural e a História da Educação, observando que o modo de manipulação das fontes pelo pesquisador é elemento-chave para uma investigação densa, problematizadora e crítica. As autoras colaboram, assim, com este estudo ao passo que salientam o fato da necessidade de se rever antigas temáticas analisadas; desconstruir "velhos objetos", de maneira a trazer à luz "novos objetos"; e avançar em novas perspectivas de análises, corroborando com a perspectiva teórica da Escola dos Annales, a qual prevê uma história-problema, com novas fontes históricas e novos sujeitos históricos, para além dos ditos oficiais. É a partir desses pressupostos que ponho luz à Vida Infantil e Vida Juvenil para pensar produções não-escolares para crianças e jovens brasileiras escolarizadas, conforme veremos na última seção deste artigo.

\section{O caminho entre Vida Infantil e Vida Juvenil}

O caminho que inicialmente me leva a Vida Infantil é repleto de gratidão e de coincidências. A gratidão se deve ao fato de eu tê-la conhecido através de uma grande parceira de grupo de pesquisa ${ }^{1}$ e amiga pessoal, a Liana Borba, professora, pesquisadora e de uma generosidade sem tamanho. Já a coincidência se deve ao fato

\footnotetext{
${ }^{1}$ Trata-se do Grupo de Pesquisa Infância, Juventude, Leitura, Escrita e Educação (GRUPEEL), coordenado pela professora Dra. Márcia Cabral da Silva (ProPEd/UERJ).

Rev. Caminhos da Educação: diálogos, culturas e diversidades, Teresina, v. 3, n. 2, p. 53-65, Mai./Ago. 2021
} 
de a referida professora e pesquisadora, em sua dissertação ${ }^{2}$, ter investigado a dimensão educativa de três periódicos femininos dos anos 1950, a saber: Jornal das Moças, Querida e Vida Doméstica, e ter, ao longo de sua pesquisa, descoberto, coincidentemente, Vida Infantil. Liana também realizou sua pesquisa na Seção de Periódicos, da FBN, e analisou, tanto Jornal das Moças quanto Vida Doméstica, a partir de seus microfilmes, e analisou Querida a partir de sua materialidade. Quando da pesquisa de Vida Doméstica, Liana analisou todas as propagandas presentes no material e, nesse movimento, acabou descobrindo Vida Infantil, que aparecia, com frequência, nas propagandas do material.

Como já é possível supor, Vida Doméstica, Vida Infantil e Vida Jwvenil eram revistas "irmãs" e eram produzidas e publicadas pela Sociedade Gráfica Vida Doméstica. As três revistas compõem o rol de publicações da editora e, como é possível observar pelos títulos, cada uma se ocupava de um público diferente: da mocidade feminina à juventude, passando pela infância, a Sociedade Gráfica Vida Doméstica visava estar presente nos lares brasileiros.

Ao descobrir Vida Infantil a partir de Vida Doméstica, Liana ficou curiosa em saber do que se tratava aquela outra publicação iniciada pela sociedade gráfica que estudava. Contudo, para seu doutoramento, Liana seguiu outro rumo: optou por se debruçar na revista Pais \& Filhos ${ }^{3}$. Desse modo, em uma de nossas conversas, argumentei que tinha o interesse em fazer o curso de mestrado e que gostaria de estudar a infância, muito por conta dos estudos já realizados no âmbito do Grupo de Pesquisa Infância, Juventude, Leitura, Escrita e Educação (GRUPEEL) e pela minha atuação como professora do Ensino Fundamental I ${ }^{4}$. Imediatamente, Liana me falou

\footnotetext{
2 SANTOS, Liana Pereira Borba dos. Mulheres e revistas: a dimensão educativa dos periódicos femininos Jornal das Moças, Querida e Vida Doméstica nos anos 1950. 2011. 170f. Dissertação (Educação) - Programa de Pós-graduação em Educação, Universidade do Estado do Rio de Janeiro, Rio de Janeiro, 2011.

${ }^{3}$ SANTOS, Liana Pereira Borba dos. Infância e família em revista: Pais \& Filhos (1968-1989). 2018. 399f. Tese (Educação) — Programa de Pós-graduação em Educação, Universidade do Estado do Rio de Janeiro, Rio de Janeiro, 2018.

${ }^{4}$ Sou professora dos Anos Iniciais do Colégio de Aplicação da Universidade Federal do Rio de Janeiro (CAp/UFRJ).
}

Rev. Caminhos da Educação: diálogos, culturas e diversidades, Teresina, v. 3, n. 2, p. 53-65, Mai./Ago. 2021 
sobre a tal Vida Infantil que houvera descoberto ao pesquisar Vida Doméstica. Assim, ela foi capaz de me deixar curiosa em relação ao periódico: que título é esse?! Que vida infantil seria retratada na revista? Que revista era essa? E, diante da minha curiosidade, fui à Seção de Periódicos da FBN investigar que tal Vida Infantil era essa. Encontrei ali, no meu primeiro contato com a revista, o meu objeto e fonte de pesquisa, objeto pelo qual ficaria encantada enquanto pesquisadora e me renderia frutos tão bons. Até hoje agradeço Liana por ter provocado este encontro tão incrível!

Após o encontro e a decisão de mergulhar no mundo de Vida Infantil, me tornei visitante assídua da seção de Periódicos e, lá, pude viver experiências de pesquisa que apenas o espaço de um arquivo físico é capaz de proporcionar. Além de poder estar em um ambiente próprio para a leitura e a escrita, aspectos característicos de uma pesquisa acadêmica, pude ter acesso à materialidade da revista, o que é, sem dúvida, uma das melhores partes de poder pesquisar em arquivos físicos. Nesse sentido, coaduno com Almeida (2021) ao defender que

As ações de preservar memórias em papel e, ao mesmo tempo, permitir o acesso a essas materialidades configuram os maiores compromissos dos Arquivos, afinados aos princípios de cidadania, fundamentais em sociedades democráticas (p. 13).

Assim, a seção de Periódicos onde realizei a pesquisa tinha dupla função: a não só de salvaguardar os periódicos ali presentes, como também a de possibilitar o acesso direto à fonte material, experiência esta que só pode ser vivida em arquivos e acervos físicos. Isso não significa que arquivos e acervos digitais não tenham sua importância; de fato, poder ter acesso a documentos que talvez não pudessem ser consultados devido à distância ou a documentos antigos, cujo manuseio seria mais dificultoso, é uma das formas de garantir e democratizar o acesso a diversos pesquisadores ao redor do mundo. Contudo, poder acessar a fonte em sua forma "crua" é uma experiência interessante.

[O trabalho nos arquivos físicos é um] trabalho de artesania, que se coloca na contramão dos processos de informatização que avançam também nas práticas arquivísticas. [...] os velhos papéis não interessam apenas pelas informações que contém, poder manuseá-los é uma importante experiência sensorial para aquele que se dedica à pesquisa. (ALMEIDA, 2021, p. 14) 
Almeida (2021) classifica a possibilidade de pegar nossos objetos e fontes como uma "experiência sensorial" e, de fato, o é, ainda que tenhamos que fazer uso de luvas e máscaras para manuseá-los com vistas à sua preservação. Além disso, importa chamar atenção para o fato de ao observarmos materiais presentes em arquivos físicos sermos capazes de observar, de maneira viva, marcas causadas pelo tempo, marcas estas que, em arquivos e acervos digitais talvez não consigamos enxergar com tanta ênfase.

Destaco, enfim, que não se trata de polarizar formas de pesquisa. Pelo contrário, a ideia é ressaltar possibilidades de pesquisas, seja via arquivo físico ou digital, de modo que se considere mais como um processo de união e complementação do que de exclusão e preterimento.

Assim, após o meu encontro com Vida Infantil, pude me debruçar em tudo aquilo que esta fonte poderia me proporcionar, na condição de material indiciário do modo como se pensava a infância naquele contexto histórico e social. Aquelas perguntas iniciais que me fizeram ficar instigada em relação ao periódico foram importantes até certo ponto. Contudo, elas se expandiram e me permitiram lançar uma hipótese: a de que Vida Infantil era uma revista de caráter híbrido, tal como a própria infância retratada na revista. O periódico buscava ser consumido por crianças escolarizadas e vistas como "futuro da nação". Logo, não bastava entreter as crianças com conteúdos rasos e superficiais, mas, sim, colaborar com seu processo educativo e formativo. Deste modo, Vida Infantil apresentava uma variedade de seções que, juntas, buscavam cumprir os objetivos vislumbrados por ela: os de divertir, educar e instruir ${ }^{5}$.

A composição de Vida Infantil parecia seguir um padrão discursivo e editorial que dialogava com os objetivos propostos. Nesse sentido, todos os elementos que a compunham são passíveis de observação, seja tanto em relação às interações verbais

\footnotetext{
${ }^{5}$ Trata-se do subtítulo da revista, instituído a partir de 1948. Neste sentido, cabe ressaltar algumas seções como "História do Brasil para Crianças", "Sua página de exercícios" e "A matemática sorri para você" (que, após o lançamento de Vida Juvenil, em 1949, migrou para esta).
}

Rev. Caminhos da Educação: diálogos, culturas e diversidades, Teresina, v. 3, n. 2, p. 53-65, Mai./Ago. 2021 
propostas nas seções (BAKHTIN, 2003) quanto aos elementos paratextuais, como as ilustrações e o jogo de cores e fontes (GENETTE, 2009). Destaque-se, contudo, as propagandas veiculadas na revista. Assim como Liana descobriu Vida Infantil através das propagandas de Vida Doméstica, foi possível descobrir Vida Juvenil a partir de Vida Infantil.

O caráter endógeno das propagandas veiculadas em todas as publicações da Sociedade Gráfica Vida Doméstica pode ser visto uma marca da editora. Logo, a partir de 1948 surgiram as propagandas de Vida Juvenil - última e mais recente publicação da editora, cujo lançamento se deu em janeiro de 1949. A curiosidade tomou nova forma: do que se tratava Vida Juvenil? No que se diferenciava e se assemelhava à Vida Infantil?

Quando estava finalizando o mestrado, decidi tentar o processo seletivo para o doutorado, cujo objeto e fonte seria, sem dúvidas, Vida Juvenil. Assim, pude observar outra característica da pesquisa em arquivos físicos: poder, em uma mesma visita à Biblioteca, pegar outros materiais e explorá-los. Então, ao folhear Vida Infantil eu podia, também, folhear Vida Juvenil, embora não fosse ainda minha fonte de pesquisa principal. Curioso pensar que se soubesse que enfrentaríamos uma pandemia um ano após minha defesa de dissertação, eu teria aproveitado melhor as oportunidades de contato com Vida Juvenil.

Destaca-se, então, uma das dificuldades de ter seu material de pesquisa sob guarda de arquivos e acervos físicos: a impossibilidade de acessá-lo se não for até o local. Em tempos de pandemia é algo a se considerar. Cheguei, inclusive, a pensar em desistir de Vida Juvenil e me debruçar em algum outro periódico disponível na Hemeroteca Digital da $\mathrm{FBN}^{6}$. Contudo, diante de tanto apreço à editora e às publicações dela e curiosidade em relação à Vida Juvenil, me coloco esperançosa de poder continuar com este objeto e fonte. $\mathrm{Na}$ próxima seção será possível observarmos, mais profundamente, nos referidos periódicos.

\footnotetext{
${ }^{6}$ Disponível em: https://bndigital.bn.gov.br/hemeroteca-digital/ 


\section{De olho nas fontes}

Após traçar o panorama em relação ao meu encontro com as revistas, cabe apresentá-las e fazer breves reflexões acerca delas. Vida Infantil (1947-1960) e Vida Juvenil (1949-1959) foram duas das três revistas de responsabilidade da Sociedade Gráfica Vida Doméstica Ltda ${ }^{7}$. Como anunciado anteriormente, Vida Doméstica ${ }^{8}$ (1920-1963) também fazia parte do rol de publicações da editora e tinha como público-alvo mulheres e moças das camadas média e alta da sociedade carioca e, mais ainda, brasileira.

Segundo o Dicionário Online de Português, Dicio ${ }^{9}$, o termo Vida representa o “conjunto dos hábitos e costumes de alguém; maneira de viver”. Destarte, é possível pensarmos o uso desse termo nos títulos das revistas da editora (inclusive no próprio nome da sociedade gráfica): trata-se de revistas que intentavam apresentar "hábitos e costumes" da infância, do jovem e da mulher, de modo a salientar e dialogar com a "maneira de viver" desses três grupos.

Como se nota a partir do título das revistas, a editora buscava produzir materiais para diferentes públicos, a despeito dos diferentes períodos. Da mocidade feminina à juventude, passando pela infância, a Sociedade Gráfica Vida Doméstica visava estar presente nos lares brasileiros. Nesse sentido, Hallewell (1985) já apontava para a segregação dos grupos de consumidores por faixa etária, prática recorrente, à época, e que podia ser observada pelo número crescente de revistas e coleções que se dividiam tanto pela idade quanto pelo sexo (SOUZA, 2019).

\footnotetext{
${ }^{7}$ A Sociedade Gráfica Vida Doméstica Ltda. tinha sede no Distrito Federal e tinha como fundador o empreendedor Jesus Gonçalves Fidalgo. Na condição de diretor responsável, contudo, não aparecia o nome de Jesus Fidalgo e, sim, de seu filho, Carlos Gonçalves Fidalgo, que ficava a frente das três revistas.

${ }^{8}$ Vida Doméstica foi uma revista brasileira que circulou mensal (posteriormente, quinzenal e semanalmente), cuja sede se localizava no Rio de Janeiro e era voltada para o público feminino. Circulou no país entre 1920 e 1963. Mais informações, conferir em SANTOS, Liana Pereira Borba dos. Mulheres e revistas: a dimensão educativa dos periódicos femininos Jornal das Moças, Querida e Vida Doméstica nos anos 1950. Dissertação de mestrado em educação. Rio de Janeiro: Universidade do Estado do Rio de Janeiro, 2011.

${ }^{9}$ Disponível em: <https://www.dicio.com.br/vida/>. Acesso em: 30 de abril de 2018.

Rev. Caminhos da Educação: diálogos, culturas e diversidades, Teresina, v. 3, n. 2, p. 53-65, Mai./Ago. 2021
} 
Vida Infantil, por um lado, foi uma revista voltada para as crianças escolarizadas que tivessem acesso a esse tipo de material. De novembro de 1947 a junho de 1951, a revista circulava com uma periodicidade mensal; já a partir de julho de 1951 passou a ser quinzenal.

Vida Juvenil, por outro lado, buscava ser consumida por adolescentes e jovens de ambos os sexos, e, também, escolarizadas e que estivessem se encaminhando para o mercado de trabalho. A pesquisa acerca de Vida Juvenil se encontra bastante inicial, então ainda não foi possível observar, com maior respaldo, a periodicidade da revista. Contudo, a partir de pesquisa preliminar supõe que seguia uma periodicidade mensal.

No que concerne aos aspectos observáveis a um público escolarizado, notamse elementos convergentes entre as revistas. Tanto Vida Infantil quanto Vida Juvenil apresentavam seções de cunho divertido, educativo e instrutivo. Nesse sentido, o lema de Vida Infantil registrava que a revista visava Divertir, Educar e Instruir, o que poderia ser ampliado para Vida Juvenil. Observe-se o subtítulo adotado pela revista a partir de dezembro de 1948 (figura 1):

Figura 1: Capa de Vida Infantil

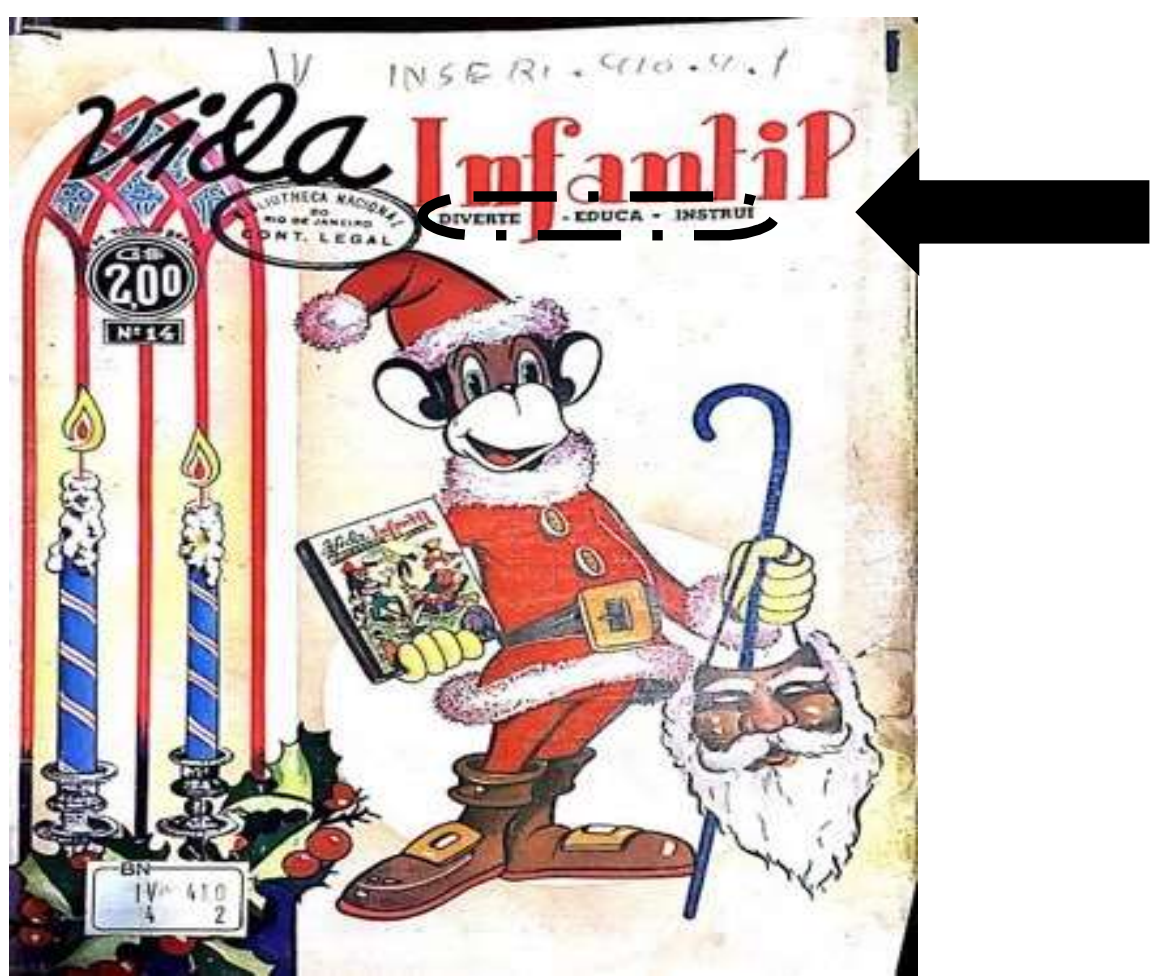

Fonte: Vida Infantil. Número 14, dez/1948, capa. Depositário: FBN 
Em Vida Infantil, a diversão, de maneira geral, ficava a cargo das Histórias em Quadrinhos e das piadas, ainda que, mesmo nas seções voltadas para a educação e instrução, o caráter divertido e lúdico não ficasse de lado; já a educação e a instrução se davam a partir de seções de conteúdo escolar, histórias de cunho moral e, ainda, algumas Histórias em Quadrinhos, uma vez que a diversão, a educação e a instrução se davam de maneira integrada. As principais seções de cunho educativo e instrutivo são "História do Brasil para Crianças", analisadas na dissertação, "Sua página de exercícios" e "A matemática sorri para você", que, posteriormente, migrou para Vida Juvenil quando do lançamento desta.

Vida Juvenil, por sua vez, também seguia uma perspectiva híbrida, mas com seções mais coerentes com o público visado. A revista também apostava em colunas de "reforço escolar", como "Lendo e Aprendendo (seção de artigos versando sobre matérias dos cursos médios)" e "A matemática sorri para você", advinda de Vida Infantil, mas cujo conteúdo se mostrava, possivelmente, mais denso e adequado ao público juvenil. Ademais, Vida Juvenil contava com a seção "Escolha sua profissão", o que indiciava o público-alvo, assim como, os preceitos da revista para a juventude: aceirar a formação de jovens bem educados, instruídos e "úteis" à pátria.

A partir da relação tecida entre as revistas, tem-se a ideia de que uma buscava agir de maneira relacional e complementar à outra. Isto significa que é possível que os editores tenham começado a investir e uma publicação para um público mais velho em relação ao público de Vida Infantil para, assim, garantir uma certa continuidade no trabalho educativo e formativo.

Observa-se que desde a criação das revistas, os editores já apresentavam, explícita ou implicitamente, o projeto ideológico delas, com especial enfoque em Vida Infantil, uma vez que foi a revista com a qual foi possível tecer um diálogo mais profícuo, mas que, de maneira associativa, compreendemos Vida Juvenil. Segundo Bakhtin (2014), “a palavra é o fenômeno ideológico por excelência [, de modo que] (...) a palavra é o modo mais puro e sensível de relação social” (p. 36). Assim, a relação estabelecida entre autor-leitor se dava estritamente entre a palavra e pelas imagens, referenciadas por Chartier (2011) como os elementos tipológicos, os quais também possuem intencionalidades.

Rev. Caminhos da Educação: diálogos, culturas e diversidades, Teresina, v. 3, n. 2, p. 53-65, Mai./Ago. 2021 
Chartier (2011) também ressalta as "intenções explícitas" do impresso, com ênfase nas revistas analisadas que buscavam, cada uma à sua medida, "distrair, educar e instruir" a criança e o jovem brasileiros. Sobre as intenções explícitas, Chartier (2011) advoga que

Há (...) tensão entre dois elementos. De uma parte, o que está do lado do autor, e por vezes do editor, e que visa a impor explicitamente maneira de ler, códigos de leitura (...), seja de maneira mais sub-reptícia uma leitura precisa (...). Esse conjunto de intenções explícitas ou depositadas no próprio texto, no limite, postularia que um único leitor pudesse ser o verdadeiro detentor da verdade da leitura. (...) Mas (...) cada livro tem uma vontade de divulgação, dirige-se a um mercado, a um público, ele deve circular, deve ganhar extensão, o que significará apropriações mal governadas, contrassensos, falhas na relação entre o leitor ideal, mas no limite singular, e de outra parte o público real que deve ser o mais amplo possível. (p. 245) (grifos meus)

A partir do excerto acima, é possível pensarmos à luz do conjunto de intenções explícitas e, até mesmo as implícitas, depositadas nas revistas, considerando o públicoleitor ideal, seus conteúdos, enredos, contextos, gêneros textuais, imagens e ilustrações, com vistas à formação de um determinado público consumidor: crianças e jovens escolarizadas, compreendidas como o futuro da nação. De todo modo, Chartier (2011) chama a atenção para o fato de que o texto é circular e, dessa maneira, encontra pessoas diversas na condição de público, de modo que as apropriações se dão de modo diferente, "malgovernadas", sem o controle daquele que, a priori, formulou o impresso. A apropriação é, portanto, singular, ativa e reativa e, bem como afirma Bakhtin (2004), dialógica. É partir dessa perspectiva, dialógica, enunciativa e ideológica, enfim, que se buscou analisar Vida Infantil quando da dissertação e, agora, Vida Juvenil, na pesquisa de doutorado.

\section{Considerações finais}

Espera-se que as análises empreendidas tenham podido iluminar elementos concernente à pesquisa a partir de dois aspectos: 1) do próprio ato de pesquisar, compreendendo limites e alcances da pesquisa em arquivos físicos; 2) dos modos de análise e dos resultados encontrados na pesquisa. Ainda que tenha sido um artigo com 
uma escrita mais do campo pessoal, foram utilizados autores para se construir o panorama proposto.

A partir da discussão acerca do primeiro ponto, ressalta-se o espaço de privilégio quando da pesquisa em arquivos físicos, por meio dos quais é possível agregar a experiência sensorial ao ato de pesquisar. Contudo, foi pontuado, também, uma limitação da pesquisa em arquivos físicos: a de se pesquisar em época de pandemia, a qual temos vivido desde 2020. Este impedimento atual tem atrasado o meu contato com Vida Juvenil, por exemplo, mas cabe ressaltar que Vida Infantil foi e é capaz de me possibilitar este encontro, ainda que de maneira "remota", por meio de propagandas daquela.

Já no segundo ponto, buscou-se por luz às revistas em destaque, de modo a apresentá-las enquanto materiais sociais de relevo para se pensar a produção para crianças e jovens, no período (final da década de 1940). Buscou-se destacar algumas características dos periódicos, como o hibridismo e o investimento em seções de reforço escolar e de formação do cidadão. Assim, o reforço escolar de Vida Infantil pode ser ilustrado por "Sua página de exercícios", a qual continha exercícios escolares de português e matemática, e a formação do pequeno cidadão podia ser vista em "História do Brasil para Crianças", na qual apresentavam-se "heróis nacionais", com vistas à reprodução por parte das crianças. Já em Vida Juvenil, o reforço escolar podia ser exemplificado por "Lendo e Aprendendo (seção de artigos versando sobre matérias dos cursos médios)" e a formação do futuro jovem da nação, em "Escolha sua profissão".

\section{Referências}

ALMEIDA, Dóris Bittencourt. Percursos de um Arq-Vivo: entre arquivos e experiências na pesquisa em história da educação. 1. ed. Porto Alegre: Editora Letra1, 2021. 164 p.

BAKHTIN, M. M. Marxismo e Filosofia da Linguagem: problemas fundamentais do método sociológico da linguagem. 16a Ed. São Paulo: Hucitec, 2014.

BLOCH, Marc. Apologia da história on o ofício de historiador. Jorge Zahar Ed, 2001. 
CERTEAU, Michel. “A operação histórica”. In: - A Escrita da História. Rio de Janeiro, Forense Universitária, 1982.

CHARTIER, Roger (org). Práticas da Leitura. 5a Ed. São Paulo: Estação Liberdade, 2011.

DICIONÁRIO ONLINE DE PORTUGUÊS. Vida. Disponível em: $<$ www.dicio.com.br/vida>. Acesso em: 30 de abril de 2018.

GENETTE, Gérard. (2009). Paratextos editoriais. São Paulo: Ateliê Editorial.

GINZBURG, Carlo. (1976). O queijo e os vermes. O cotidiano e as idéias de um moleiro perseguido pela Inquisição. Cia das Letras: SP.

GOMES, Angela de Castro. As Aventuras de Tibicuera: literatura infantil, história do Brasil e política cultural na Era Vargas. Revista USP, São Paulo, no 59, p. 116-133, setembro/novembro 2003.

HALLEWELL, Laurence. O livro no Brasil: sua história. São Paulo: Edusp, 1985.

NUNES, Clarice; CARVALHO, Marta Maria Chagas de. "Historiografia da educação e fontes". In: GONDRA, José Gonçalves (org.). Pesquisa em história da educação no Brasil. Rio de Janeiro: DP\&A, 2005.

SANTOS, Liana Pereira Borba dos. Mulheres e revistas: a dimensão educativa dos periódicos femininos Jornal das Moças, Querida e Vida Doméstica nos anos 1950. 2011. 170f. Dissertação (Educação) - Programa de Pós-graduação em Educação, Universidade do Estado do Rio de Janeiro, Rio de Janeiro, 2011.

SANTOS, Liana Pereira Borba dos. Infância e familia em revista: Pais \& Filhos (1968-1989). 2018. 399f. Tese (Educação) — Programa de Pós-graduação em Educação, Universidade do Estado do Rio de Janeiro, Rio de Janeiro, 2018.

AUTOR, 2019.

\section{Fonte documental}

VIDA INFANTIL. Rio de Janeiro: Sociedade Gráfica Vida Doméstica Ltda, ano 2, n. 14, dez. 1948

RECEBIDO: 01/04/2021

APROVADO:03/05/ 2021
RECEIVED: 01/04/2021

APPROVED: 03/05/ 2021
RECIBIDO: 03/04/ 2021

APROBADO: 03/05/ 2021 